\title{
EXPERIMENTAL INVESTIGATIONS OF DYNAMIC PERFORMANCE OF POLYPROPYLENE BALL BEARINGS
}

\author{
Nesrine GaAliche ${ }^{1,2}$, Subramanian Chithambaram ${ }^{3}$, \\ RAOUF FATHALLAH ${ }^{1,4 *}$ \\ ${ }^{1}$ Unit of Mechanical Production Engineering and Materials, \\ National School of Engineers of Sfax, University of Sfax, \\ Soukra Road Km 4 BP. 1173-3038, Tunisia \\ ${ }^{2}$ Department of Mechanical Engineering, University of Bahrain, \\ P.O. Box 32038, Sakheer, Kingdom of Bahrain \\ ${ }^{3}$ Department of Mechanical Engineering, School of Engineering, \\ Bahrain Polytechnic, PO Box 33349, Isa Town, Kingdom of Bahrain \\ ${ }^{4}$ National Engineering School of Sousse, University of Sousse, \\ BP 264 Sousse Erriadh 4023, Tunisia
}

[Received: 22 October 2018. Accepted: 03 February 2020]

doi: 10.7546/JTAM.50.20.01.03

\begin{abstract}
Thermoplastic bearings are finding its practical importance in light duty applications due to their good tribological property. Investigating the dynamic performance of thermoplastic bearing is crucial due to the heterogeneous material structure. In this work, effort has been made to investigate the dynamic performance of healthy and faulty polypropylene bearings. Condition monitoring of bearings is carried out using the developed test rig. The influence of the size of the defect, effect of frequency and load are investigated using vibration analysis. Radial accelerations and velocities were measured by accelerometers under different loads and frequencies. Test results reveal that FFT spectrum allows to localize the defect in the outer or the inner race and to characterize the defect severity.
\end{abstract}

KEY WORDS: thermoplastic bearing, dynamic performance, vibration condition monitoring, characteristic defect frequencies.

\section{NOMENCLATURE \\ $F_{s}=$ Shaft rotational frequency $(\mathrm{Hz})$, \\ $F_{I}=$ Ball pass frequency inner race $(\mathrm{Hz})$, \\ $F_{o}=$ Ball pass frequency outer race $(\mathrm{Hz})$, \\ $F T F=$ Fundamental train Frequency $(\mathrm{Hz})$, \\ $N=$ Number of balls,}

$n=$ Speed (rpm),

$B_{d}=$ Ball diameter $(\mathrm{mm})$,

$P_{d}=$ Pitch diameter $(\mathrm{mm})$,

$\theta=$ Contact angle.

\footnotetext{
*Corresponding author e-mail: raouf.fathallah@gmail.com
} 


\section{INTRODUCTION}

Thermoplastic ball bearings are widely used in the mechanical industry, particularly, in the aerospace, automotive, naval, medical equipment, food processing and home appliance systems. Beyond their lightweight and self-lubricating property thermoplastic ball bearings offer several advantages as quiet operation, excellent corrosion resistance, appreciable hardness and mass production capability $[1,2]$. Thus, they are replacing progressively metallic bearings in many sectors. Both plastic and metallic bearings are subject to high cyclic stresses between the rolling elements and raceways leading frequently to failure in rotating machines [3]. Fatigue due to vibration and wear are the two potential sources of failure in thermoplastic bearings. Continuous vibrations are harmful to machines and structures since they result in wastage of energy and cause fatigue failure [4]. Therefore, controlling vibrations and reducing friction is a serious engineering challenge [5]. The monitoring of bearings conditions, such as vibration, acoustic, temperature measurements, and wear debris analysis has been extensively studied by many researchers [6-13]. In this framework, the vibration monitoring approach is the most commonly applied predictive maintenance method for fault-detection employed in rotor-bearing systems. It's mainly because of its ease of application, the potential benefit of improving safety and decreasing maintenance cost [14]. Moreover, this technique has the advantage to localize the fault and to determine its severity [15].

Early researchers have focused on developing the kinematics and dynamics equations between the bearing's rotating elements. The equations developed by White [16] and Harris [17] were used to detect the defect frequency for radial ball bearings. This analytical model predicts the fundamental defect frequencies excited by faults or irregularities in the races or the rollers.

Tandon and Choudhury [18] developed an analytical model based on predicting the defect frequencies of different elements of bearings having localized defects. The amplitudes at these frequencies are also predicted for various defect locations. It can predict discrete frequency spectrum showing high vibration amplitudes at the fundamental defect frequencies and their harmonics. The analytical model developed was later improved to predict the frequency spectrums of bearings with and without distributed defects [19]. Moreover, it was shown that peak amplitudes at the bearing defect frequencies are significantly correlated to the severity of the fault.

Recent research work and investigations on vibration response of plastic bearings has been carried out by Raveendran et al. [20]. The authors compared the performance of polyetheretherketone (PEEK) and polytetrafluoroethylene (PTFE) polymeric deep groove bearings with stainless steel bearings. Vibration study, operating speed and acoustic analysis was used to investigate the failure and the wear behavior 
of bearings. The experimental investigations revealed that the vibration amplitude the PTFE bearing is higher than that of PEEK bearing. However, the detected running speed of PEEK bearings is less stable than PTFE bearings.

Even though most of the previous works have been carried out on the use of vibration condition monitoring system for metallic bearing, only few works have been conducted to investigate the dynamic performance of polymer bearings. In an attempt to extend those studies using experimental investigations, a developed test rig has been used to investigate the feature extraction of local defects of plastic bearing. This proposed approach aims at providing additional information to improve the dynamic performance of thermoplastic bearing and reduce maintenance cost of the bearings and machinery. It involves measuring radial accelerations and velocities obtained from both healthy and defective polypropylene bearings by analyzing the FTT spectrums under different applied loads and frequencies. The main advantage of the present approach is to describe accurately the mechanical state of a bearing, which allows reducing vibrations and preventing catastrophic failure of the rotating system.

\section{The Analytical Model}

The analytical model provides the theoretical defect frequencies expressions of defective ball bearings. This approach is based on the assumption that the defect frequencies depend only on the bearing geometry and the rotor speed. For the general case, where the outer ring is stationary and the inner one is rotating, the characteristic defect frequencies are given by the following expressions that are developed by White [15] and Harris [16]:

$$
\begin{aligned}
& F_{s}=\frac{n}{60}, \\
& F_{I}=\frac{N}{2} F_{s}\left(1+\frac{B_{d}}{P_{d}} \cos \theta\right), \\
& F_{o}=\frac{N}{2} F_{s}\left(1-\frac{B_{d}}{P_{d}} \cos \theta\right), \\
& F T F=\frac{F_{s}}{2}\left(1-\frac{B_{d}}{P_{d}} \cos \theta\right) .
\end{aligned}
$$

\section{EXPERIMENTAL INVESTIGATION}

\subsection{EXPERIMENTAL TEST RIG AND INSTRUMENTATION}

The developed rig for testing the plastic ball bearing is shown in Fig. 1. The test rig has a rotating shaft with $45 \mathrm{~mm}$ length and $9 \mathrm{~mm}$ diameter. The test rig is a capable of operating at various frequencies driven by an AC Motor coupled with a speed controller. The shaft is supported between a metallic bearing on one side and a 
plastic one on the other side. The tested plastic bearing is mounted on a manufactured casing assembly made of bronze. Its inner race rotates at the shaft speed due to its press fit assembly with the shaft. The assembly is connected to a purely vertical short load arm. A load cell, linking the short to the longer arms, allows measuring the force applied to the bearing. The movable dead weight attached to the longer arm assists the variation of the applied load (Fig. 1). A piezoelectric accelerometer was fixed on the surface of the bearing housing via a magnetic base (Fig. 1). The transducer of sensitivity of $5 \mathrm{mV} / \mathrm{g}$ with measurement range $\pm 1000 \mathrm{~g}$ is linked to the FFT Analyzer, which is connected to a Data acquisition system. The vibration signals were processed and analyzed by ONEPROD xpr-300 software. The instrumental part includes an acceleration sensor, FFT spectrum analyzer, electrical drive, and a digital tachometer.

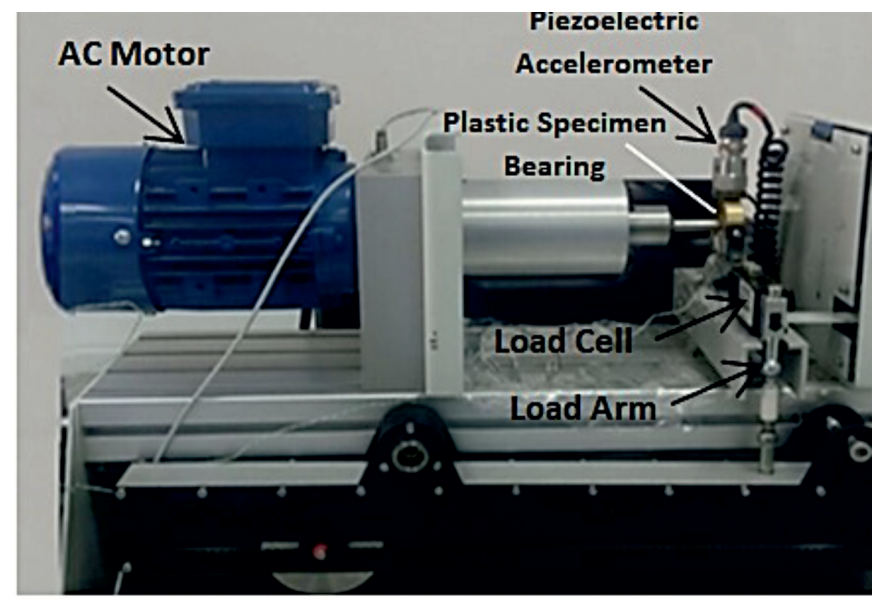

Fig. 1. The developed fatigue test rig.

\subsection{TESTED BEARING}

The dynamic tests were carried out on manufactured single row deep groove radialball bearings (Fig. 2). The both rings (the inner and the outer) and the retainer of the tested bearings were machined from extruded and injection molded round bars made from Polypropylene (PP) (Table 1) [21]. Seven glass balls were placed in the retainers. The machined bearing used in this study has the dimensional characteristics of bearing model 629 (SKF) (Table 2). 

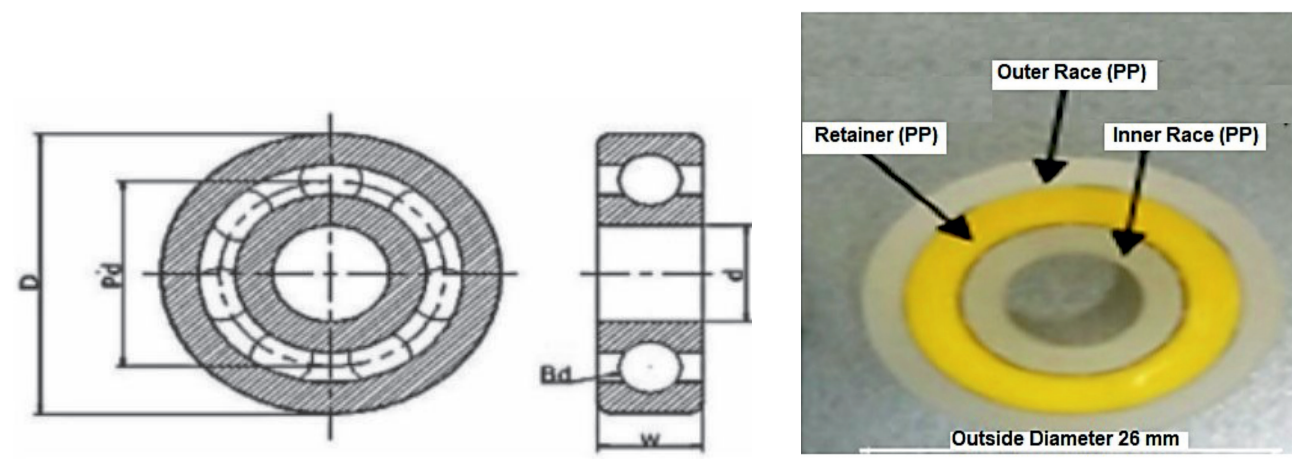

Fig. 2. The polypropylene deep groove ball bearing.

Table 1. The mechanical properties of the used polymers Polypropylene (PP) [21]

\begin{tabular}{|lc||lc|}
\hline \hline Tensile strength $(\mathrm{MPa})$ & 12 & Surface hardness & RR 85 \\
Elongation at break $(\%)$ & 600 & Heat deflection temperature $\left({ }^{\circ} \mathrm{C}\right)$ & 103 \\
Tensile modulus $(\mathrm{MPa})$ & 402 & Coefficient of thermal expansion & 200 \\
Notched izod impact strength $(\mathrm{kJ} / \mathrm{m})$ & 0.05 & Density $\left(\mathrm{g} / \mathrm{cm}^{3}\right)$ & 0.90 \\
\hline \hline
\end{tabular}

Table 2. The geometrical properties of the polypropylene deep groove bearing

\begin{tabular}{|lc||lc|}
\hline \hline Bearing dimensions & Value & Bearing dimensions & Value \\
\hline Outside diameter, $D$ & $26 \mathrm{~mm}$ & Number of balls, $N$ & 7 \\
Bore diameter, $d$ & $9 \mathrm{~mm}$ & Pitch diameter, $P_{d}$ & $18 \mathrm{~mm}$ \\
Width, $w$ & $8 \mathrm{~mm}$ & Contact angle $\theta$ & 0 \\
Ball diameter, $B_{d}$ & $4.762 \mathrm{~mm}$ & & \\
\hline \hline
\end{tabular}

\subsection{TEST CONDITIONS}

The dynamic performance was investigated for healthy and defective bearings. The faults were introduced by scratching the outer and inner raceway surfaces using an electric solder iron with a heated tip of $2 \mathrm{~mm}$ diameter and $1 \mathrm{~mm}$ on the outer and inner races of unassembled bearings as shown in Fig. 3. The hole-diameter has been measured and confirmed by using a profile projector.

Experimental investigations are initially carried out on new and healthy polypropylene bearings. These measurements are set as a reference for the other test trials where defective bearings are analyzed.

In order to investigate the effect of load on the dynamic response of the bearing, dead weight was varied to provide the specific applied load with regard to the light 


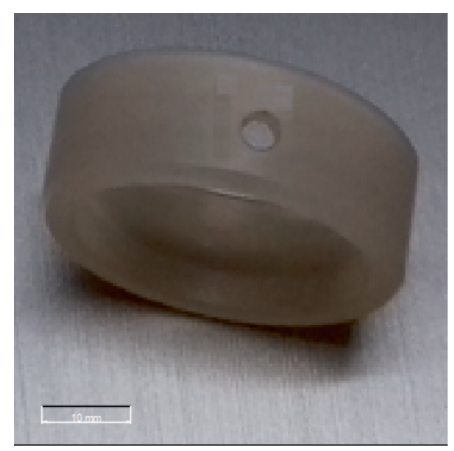

The outer race fault

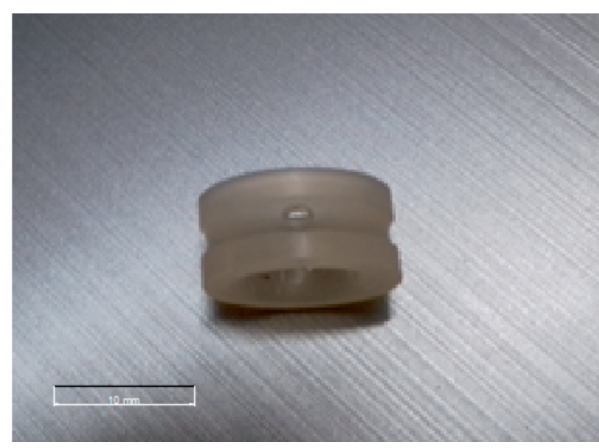

The inner race fault

Fig. 3. The outer and inner races bearing defects.

load capacity of plastic bearings used in medical equipment, food processing and home appliance applications. The first experimental set is carried out for both healthy and defective bearings with defect size of $1 \mathrm{~mm}$ and $2 \mathrm{~mm}$ on the outer race and the inner race under a load of $5 \mathrm{~N}$ tested for frequencies ranging from 10 to $25 \mathrm{~Hz}$ with an increment of $5 \mathrm{~Hz}$. Similarly, the second experimental set is carried out for both healthy and defective bearings with defect size of $1 \mathrm{~mm}$ and $2 \mathrm{~mm}$ on the outer race and the inner race under a frequency of $20 \mathrm{~Hz}$ tested for loads ranging from 5 to $20 \mathrm{~N}$ with an increment of $5 \mathrm{~N}$.

\section{Results And Discussion}

\subsection{INFLUENCE OF DEFECT SIZE ON PERFORMANCE OF THERMOPLASTIC BEAR- ING}

The frequency spectrums are measured at various frequencies and for different defect sizes on the outer ring and inner ring of ball bearings. Figures 4 to 7 show the vibration spectrums of both healthy and defective bearings with defect size of $1 \mathrm{~mm}$ and $2 \mathrm{~mm}$ on the outer race and the inner race under a load of $5 \mathrm{~N}$ tested for frequencies of $10 \mathrm{~Hz}$ to $20 \mathrm{~Hz}$. The results measured from vibration spectrums for variation in defect sizes, defect position, frequency is tabulated in Tables 4 and 5. However, the peak amplitude of vibration signal increases as frequency increases. From spectrum (Fig. 4a) and (Fig. 4b), peak in the range of bearing characteristic defect frequencies is not visualized and clearly indicates that there is no defect present in the bearing.

Generally, the faults on stationary outer races of bearings occur in the load zone due to the higher occurrence of repeated cyclic stresses [22]. Therefore, the defect in the outer race is placed in the load zone of the bearing. The vibration spectrums of bearing with outer defect size of $1 \mathrm{~mm}$ and $2 \mathrm{~mm}$ are shown in Figures (5a) and (5b), 
Experimental Investigations of Dynamic Performance of Polypropylene ...

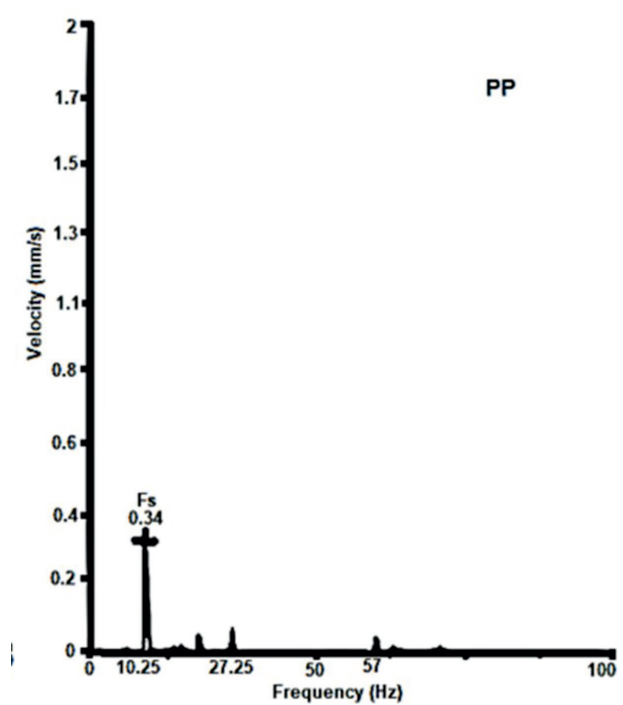

Fig. 4a. Velocity spectrum of healthy bearing at $10 \mathrm{~Hz}$ for $5 \mathrm{~N}$.

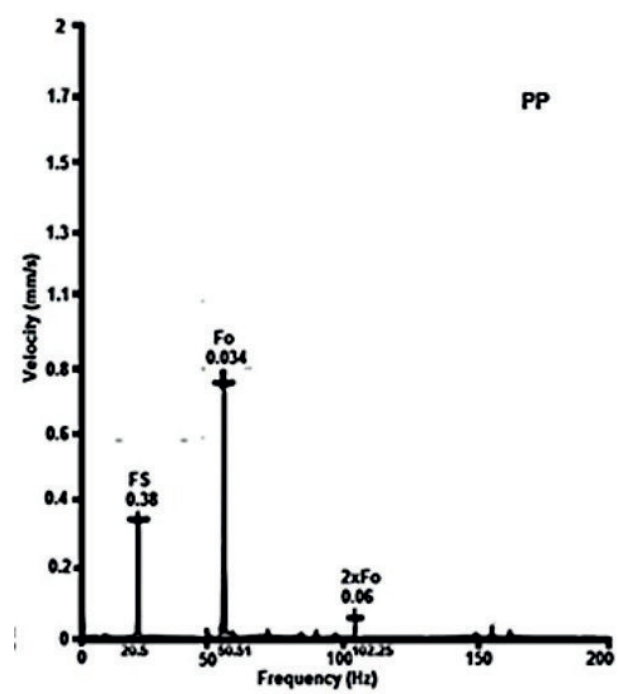

Fig. 5a. Velocity spectrum of $1 \mathrm{~mm}$ outer race defect for frequency $20 \mathrm{~Hz}$ at $5 \mathrm{~N}$.

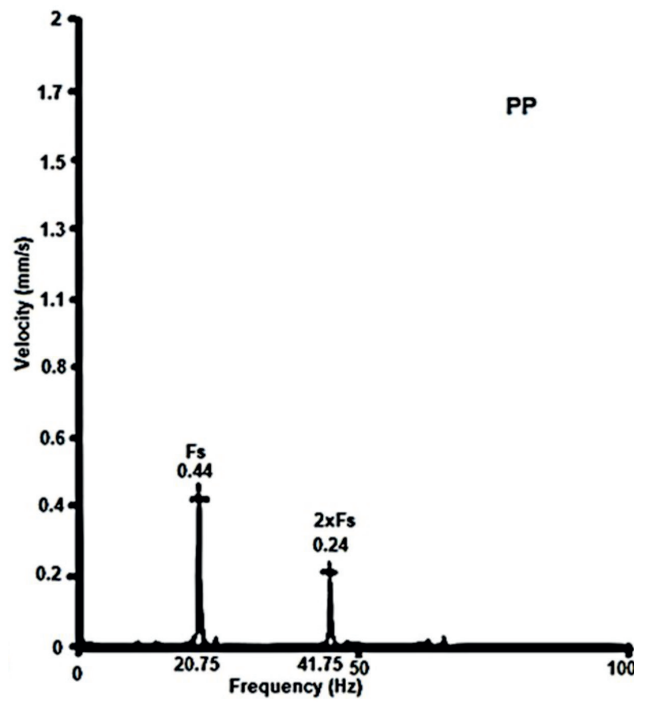

Fig. 4b. Velocity spectrum of healthy bearing at $20 \mathrm{~Hz}$ for $5 \mathrm{~N}$.

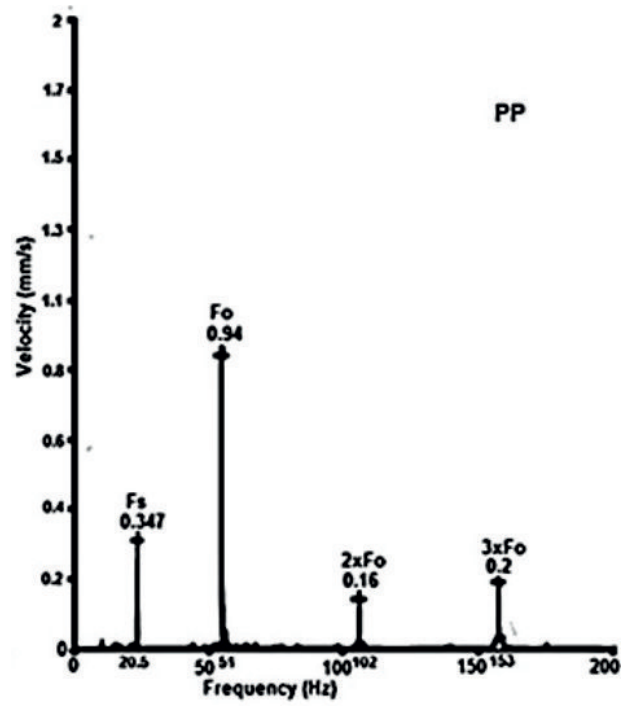

Fig. 5b. Velocity spectrum of $2 \mathrm{~mm}$ outer race defect for frequency $20 \mathrm{~Hz}$ at $5 \mathrm{~N}$. 

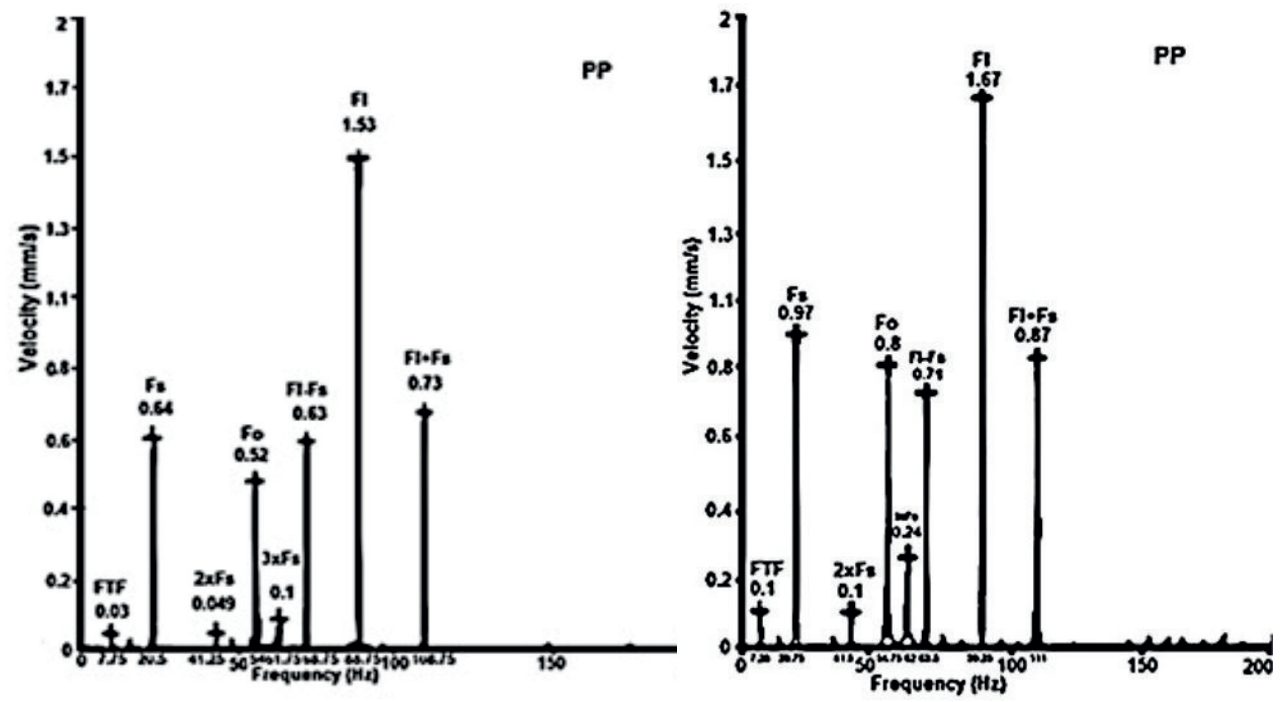

Fig. 6a. Velocity spectrum of $1 \mathrm{~mm}$ inner race defect for frequency $20 \mathrm{~Hz}$ at $5 \mathrm{~N}$.

Fig. 6b. Velocity spectrum of $2 \mathrm{~mm}$ inner race defect for frequency $20 \mathrm{~Hz}$ at $5 \mathrm{~N}$.

respectively tested for constant frequency and load. For the two defect diameters of $1 \mathrm{~mm}$ and $2 \mathrm{~mm}$, the vibration amplitudes at $F$ have reached $0.46 \mathrm{~mm} / \mathrm{s}$ and $0.5 \mathrm{~mm} / \mathrm{s}$, respectively. Hence, it is evident that the overall vibration levels have enhanced with increase in the size of the outer race defect [19].

Velocity spectrums of bearings of inner race defect with $1 \mathrm{~mm}$ and $2 \mathrm{~mm}$ are shown in Figures (6a) and (6b). The FFT spectrums are not similar to the earlier obtained spectrum with the outer race defect. Figures (6a) and (6b) show peaks at inner race defect frequencies at $88.75 \mathrm{~Hz}$ and $90.25 \mathrm{~Hz}$ corresponding to $1 \mathrm{~mm}$ and $2 \mathrm{~mm}$ inner race defect. The peak amplitude at inner race frequency increases from $1.5 \mathrm{~mm} / \mathrm{s}$ to $1.67 \mathrm{~mm} / \mathrm{s}$ as the size of the defect increases from $1 \mathrm{~mm}$ to $2 \mathrm{~mm}$. Moreover, ball pass frequency $\left(F_{I}\right)$ is modulated with the shaft frequency $\left(F_{s}\right)$ for both the defect sizes. Frequencies corresponding to sidebands are equal to $F_{I} \pm F_{s}$. If the fault is on the inner race, it will enter and leave the loading zone. While, in the loading zone, the fault generates vibration at $F_{I}$, but when it is out of this zone, less level of vibration is generated at this frequency. This leads to the apparition of peaks at $F_{I}$ with modulations. The introduction of a defect in the inner race produces a looseness of the cage, which can cause vibration at the FTF as the rolling elements accelerate and decelerate through the load zone. Therefore, shaft frequency is modulated with the $F T F$ fundamental frequency [23]. Similar kind of observations was reported for all the tested frequencies with an inner race defect and the findings are tabulated in 
Tables 4 and 5. Marginal increase in amplitude for sidebands is observed with the increase in inner race defect size. In the outer race defective bearing, sidebands are not visualized. This characteristic feature does not occur due to the fixation of the outer race; therefore, there is no amplitude modulation. This appears as a result of the unbalanced rolling elements caused by the looseness of the cage. Figs. $6 \mathrm{a}$ and $6 \mathrm{~b}$ show modulation of $F$ with $F T F$, which is caused by the rolling elements which accelerate and decelerate through the loading zone. Outer race frequency peak amplitude was observed with the introduction of an inner race defect without harmonics.

The FFT spectrums in the low frequency range for healthy and defective bearings allow the detection of the defect location based on the characteristic defect frequencies. The severity also can be detected, with regard to the peak amplitude at these frequencies.

\subsection{INFLUENCE OF SPEED ON PERFORMANCE OF THERMOPLASTIC BEARING}

Vibration spectrums of inner race of $2 \mathrm{~mm}$ defective bearing tested under a constant load of $5 \mathrm{~N}$ with different operating frequency ranging from $10 \mathrm{~Hz}$ to $15 \mathrm{~Hz}$ are shown in Figures $7 \mathrm{a}$ and $7 \mathrm{~b}$. The inner race defect frequency at $47.25 \mathrm{~Hz}$ and $66.5 \mathrm{~Hz}$ respectively was observed in the vibration spectrums (Figs. 7a and 7b). The same observations were visualized for all the tested frequencies with an inner race defect and the results are tabulated in Table 4 . The frequency of inner race defect and its

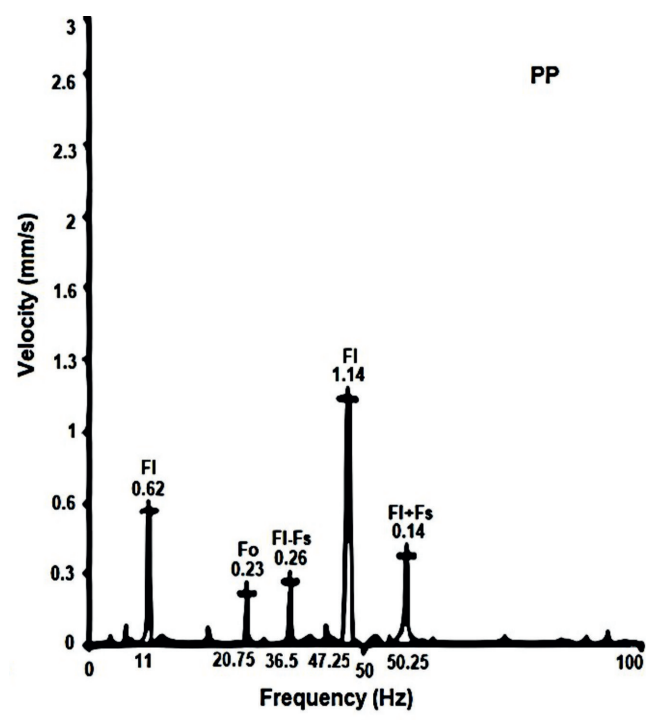

Fig. 7a. Velocity spectrum of $2 \mathrm{~mm}$ inner race defect for frequency $10 \mathrm{~Hz}$ at $5 \mathrm{~N}$.

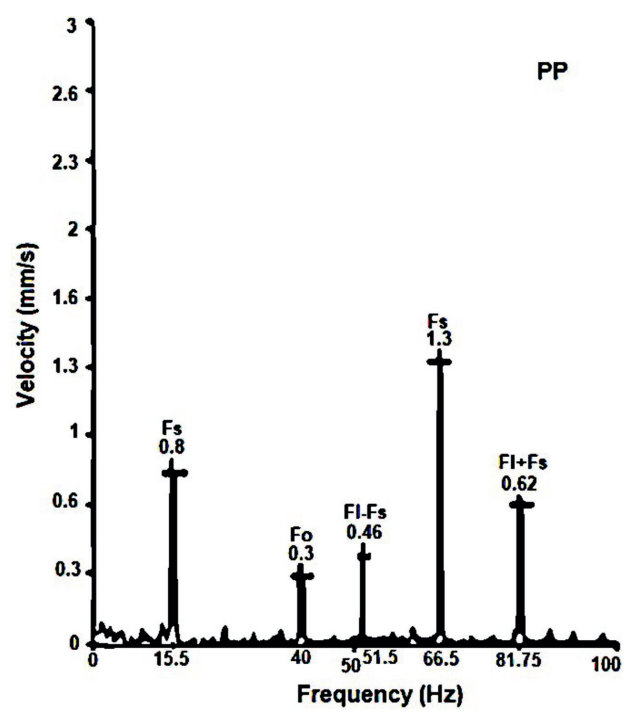

Fig. 7b. Velocity spectrum of $2 \mathrm{~mm}$ inner race defect for frequency $15 \mathrm{~Hz}$ at $5 \mathrm{~N}$. 
two sidebands obtained from the FFT analyzer for $10 \mathrm{~Hz}$ rotational frequency are $47.25 \mathrm{~Hz}, 36.5 \mathrm{~Hz}$ and $58.25 \mathrm{~Hz}$ closely match with the fault frequencies $F_{I}$ and its two sidebands calculated using the equation (2) which is $44.25 \mathrm{~Hz}, 34.25 \mathrm{~Hz}$ and $54.25 \mathrm{~Hz}$ (Table 3). The peak amplitudes at sideband frequency $\left(F_{I}-F_{s}\right.$ and $\left.F_{I}+F_{s}\right)$ increase with respect to the operating frequency [24]. Fundamental Train Frequency $(F T F)$ was also observed during the testing of bearing with inner race defect for high frequency of $20 \mathrm{~Hz}$ and $25 \mathrm{~Hz}$. The calculated defect frequencies for different types of defects and shaft rotational frequency at different speeds given by equations (1) to (4) are shown in Table 3. These frequencies are kinematic frequencies that depend on the geometry of a bearing and rotor speed. Roque et al. [25] reported that the cage rotation speed is the main cause of this deviation. These theoretical frequencies do not consider the slipping or skidding in the rotating components. Therefore, actual characteristic defect frequencies (Tables 4 and 5) slightly differ from those calculated using the aforementioned equations. Another important note on the frequencies is the bearing frequency calculations are for a perfect bearing and the small manufacturing defect will also be responsible for this deviation.

Table 3. Theoretical defective characteristics frequencies $(\mathrm{Hz})$ at different speeds

\begin{tabular}{|c|c|c|c|c|c|c|c|c|c|c|}
\hline \multirow[b]{2}{*}{$\begin{array}{l}\text { Speed } \\
\text { (rpm) }\end{array}$} & \multirow[b]{2}{*}{$\begin{array}{c}\text { Shaft } \\
\text { rotational } \\
\text { frequency } \\
F_{s}(\mathrm{~Hz})\end{array}$} & \multicolumn{9}{|c|}{ Fundamental frequency obtained from statically } \\
\hline & & $\begin{array}{c}\text { Outer } \\
\text { race } \\
\text { defect } \\
\text { freq. } F_{o}\end{array}$ & $2 \times F_{o}$ & $3 \times F_{o}$ & $\begin{array}{c}\text { Inner } \\
\text { race } \\
\text { defect } \\
\text { freq. } F_{I}\end{array}$ & $F_{I}-F_{s}$ & $F_{I}+F_{s}$ & $F T F$ & $F_{s}-F T F$ & $F_{s}+F T F$ \\
\hline 600 & 10 & 25.74 & 51.5 & 77.25 & 44.25 & 34.25 & 45.25 & 3.26 & 6.74 & 13.26 \\
\hline 900 & 15 & 38.61 & 77.22 & 115.83 & 66.38 & 51.38 & 81.38 & 4.90 & 10.1 & 19.9 \\
\hline 1200 & 20 & 51.48 & 102.96 & 154.44 & 88.51 & 68.51 & 108.51 & 6.53 & 13.47 & 26.53 \\
\hline 1500 & 25 & 64.35 & 128.7 & 193.05 & 110.64 & 85.64 & 135.64 & 8.17 & 16.83 & 33.17 \\
\hline
\end{tabular}

\subsection{INFLUENCE OF LOAD ON PERFORMANCE OF THERMOPLASTIC BEARING}

Load bearing parameter plays a crucial and inevitable part in the performance of thermoplastic ball bearing. Bearing life is affected with respect to the applied load. Vibration spectrums of inner race defective bearing tested for constant operating frequency of $20 \mathrm{~Hz}$ under different loads ranging from $5 \mathrm{~N}$ to $15 \mathrm{~N}$ with an increment of $10 \mathrm{~N}$ are shown in Figures $6 \mathrm{~b}$ and 8. The spectrums show the presence of a defect on the inner race of the bearing, which is confirmed by the presence of a peak at $F_{I}$ and its associated sidebands. Similar observations were reported for all the tested loads with an inner race defect and the findings are tabulated in Table 5. Figure 8 clearly elucidates that the peak amplitude at the inner race defect frequency increases 
Experimental Investigations of Dynamic Performance of Polypropylene ...

Table 4. The frequencies of defected bearing at $5 \mathrm{~N}$ radial load for running speeds $10 \mathrm{~Hz}$ and $25 \mathrm{~Hz}$

\begin{tabular}{|c|c|c|c|c|c|c|c|c|c|c|c|c|c|}
\hline \multirow[b]{2}{*}{ Speed } & \multirow{2}{*}{\multicolumn{3}{|c|}{ Load $5 \mid \mathrm{N}$}} & \multicolumn{10}{|c|}{ Maximum amplitude spectrum value at corresponding frequency $(\mathrm{x} \mathrm{Hz})$} \\
\hline & & & & $\begin{array}{l}\text { Freq. } \\
\mathrm{x} 1\end{array}$ & Amp. & $\begin{array}{c}\text { Freq. } \\
\mathrm{x} 2\end{array}$ & Amp. & $\begin{array}{c}\text { Freq. } \\
\text { x3 }\end{array}$ & Amp. & $\begin{array}{c}\text { Freq. } \\
F_{s}-\mathrm{x}\end{array}$ & Amp. & $\begin{array}{l}\text { Freq. } \\
F_{s}+\mathrm{x}\end{array}$ & Amp. \\
\hline \multirow{15}{*}{ 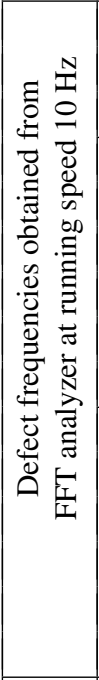 } & \multirow{3}{*}{\multicolumn{2}{|c|}{ Healthy }} & $F_{s}$ & 10.25 & 0.34 & & & & & & & & \\
\hline & & & $F_{o}$ & & & & & & & & & & \\
\hline & & & $F_{I}$ & & & & & & & & & & \\
\hline & \multirow{6}{*}{ 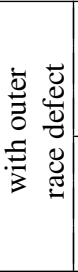 } & \multirow{3}{*}{ 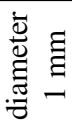 } & $F_{s}$ & 10.5 & 0.38 & & & & & & & & \\
\hline & & & $F_{o}$ & 25 & 0.4 & & & & & & & & \\
\hline & & & $F_{I}$ & & & & & & & & & & \\
\hline & & \multirow{3}{*}{ 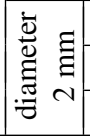 } & $F_{s}$ & 10.5 & 0.403 & & & & & & & & \\
\hline & & & $F_{o}$ & 25.25 & 0.52 & & & & & & & & \\
\hline & & & $\bar{F}$ & & & & & & & & & & \\
\hline & \multirow{6}{*}{ 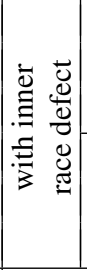 } & \multirow{3}{*}{ 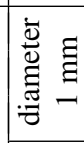 } & $F_{s}$ & 10.75 & 0.54 & & & & & & & & \\
\hline & & & $F_{o}$ & 27.25 & 0.11 & & & & & & & & \\
\hline & & & $F_{I}$ & 47.75 & 0.9 & & & & & 37.75 & 0.1 & 58 & 0.28 \\
\hline & & \multirow{3}{*}{ 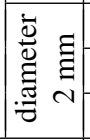 } & $F_{s}$ & 11 & 0.62 & & & & & & & & \\
\hline & & & $F_{o}$ & 28.75 & 0.23 & & & & & & & & \\
\hline & & & $F_{I}$ & 47.25 & 1.14 & & & & & 36.5 & 0.28 & 58.25 & 0.4 \\
\hline \multirow{17}{*}{ 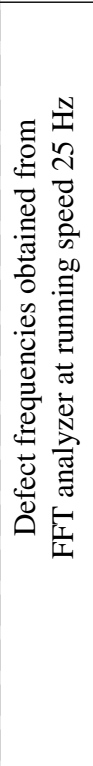 } & \multirow{3}{*}{\multicolumn{2}{|c|}{ Healthy }} & $F_{s}$ & 25.25 & 0.5 & 50.5 & 0.29 & & & & & & \\
\hline & & & $F_{o}$ & & & & & & & & & & \\
\hline & & & $F_{I}$ & & & & & & & & & & \\
\hline & \multirow{6}{*}{ 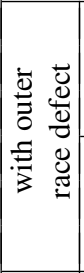 } & \multirow{3}{*}{ 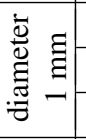 } & $F_{s}$ & 25.5 & 0.54 & 50.25 & 0.35 & & & & & & \\
\hline & & & $F_{o}$ & 64.25 & 1 & 128.25 & 0.1 & & & & & & \\
\hline & & & $F_{I}$ & & & & & & & & & & \\
\hline & & \multirow{3}{*}{ 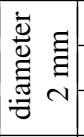 } & $F_{s}$ & 25.5 & 0.63 & 51 & 0.14 & & & & & & \\
\hline & & & $F_{o}$ & 64 & 1.2 & 128 & 0.18 & 192.25 & 0.25 & & & & \\
\hline & & & $F_{I}$ & & & & & & & & & & \\
\hline & \multirow{8}{*}{ 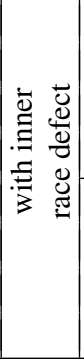 } & \multirow{4}{*}{ 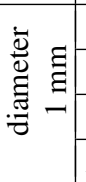 } & $F_{s}$ & 25.5 & 0.79 & 51 & 0.13 & & 0.22 & & & & \\
\hline & & & $F_{o}$ & 66 & 0.74 & & & & & & & & \\
\hline & & & $F_{I}$ & 111 & 1.8 & & & & & 86.25 & 0.85 & 136.25 & 0.91 \\
\hline & & & $F T F$ & 9.5 & 0.15 & & & & & 16 & 0.08 & 34 & 0.18 \\
\hline & & \multirow{4}{*}{ 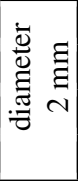 } & $F_{s}$ & 26 & 1.1 & 51.25 & 0.2 & 76.75 & 0.3 & & & & \\
\hline & & & $F_{o}$ & 66.75 & 0.85 & & & & & & & & \\
\hline & & & $F_{I}$ & 113 & 1.94 & & & & & 87.25 & 0.96 & 138.25 & 1.1 \\
\hline & & & $F T F$ & 10 & 0.27 & & & & & 15 & 0.11 & 35.25 & 0.3 \\
\hline
\end{tabular}


Table 5. The frequencies of defected bearing at radial load of $10 \mathrm{~N}$ and $20 \mathrm{~N}$ for running speed $20 \mathrm{~Hz}$

\begin{tabular}{|c|c|c|c|c|c|c|c|c|c|c|c|c|c|}
\hline \multirow[b]{2}{*}{$\begin{array}{l}\text { Radial } \\
\text { speed }\end{array}$} & \multirow{2}{*}{\multicolumn{3}{|c|}{$\mathrm{S}$ speed $20 \mathrm{~Hz}$}} & \multicolumn{10}{|c|}{ Maximum amplitude spectrum value at corresponding frequency $(\mathrm{x} \mathrm{Hz})$} \\
\hline & & & & \multirow{2}{*}{\begin{tabular}{|c|}
$\begin{array}{c}\text { Freq. } \\
\mathrm{x} 1\end{array}$ \\
20.5 \\
\end{tabular}} & \multirow{2}{*}{$\begin{array}{c}\text { Amp. } \\
0.5\end{array}$} & \multirow{2}{*}{\begin{tabular}{|c}
$\begin{array}{c}\text { Freq. } \\
\mathrm{x} 2\end{array}$ \\
40.25 \\
\end{tabular}} & \multirow{2}{*}{$\begin{array}{c}\text { Amp. } \\
0.29\end{array}$} & \multirow[t]{2}{*}{\begin{tabular}{|c|} 
Freq. \\
x3 \\
\end{tabular}} & \multirow[t]{2}{*}{ Amp. } & \multirow[t]{2}{*}{\begin{tabular}{|c|} 
Freq. \\
$F_{s}$-X \\
\end{tabular}} & \multirow[t]{2}{*}{ Amp. } & \multirow[t]{2}{*}{$\begin{array}{l}\text { Freq. } \\
F_{s}+\mathrm{x} \\
\end{array}$} & Amp \\
\hline \multirow{15}{*}{ 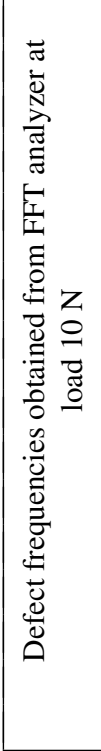 } & \multirow{3}{*}{\multicolumn{2}{|c|}{ Healthy }} & $F_{s}$ & & & & & & & & & & \\
\hline & & & $F_{o}$ & & & & & & & & & & \\
\hline & & & $F_{I}$ & & & & & & & & & & \\
\hline & \multirow{4}{*}{ : } & \multirow{4}{*}{ 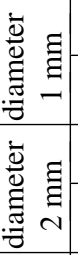 } & $F_{s}$ & 20.75 & 0.65 & 40.5 & 0.4 & & & & & & \\
\hline & & & $F_{o}$ & 51.25 & 1.1 & 102.25 & 0.1 & 153.5 & 0.02 & & & & \\
\hline & & & $F_{s}$ & 20.5 & 0.79 & 42 & 0.32 & 62.25 & 0.12 & & & & \\
\hline & & & $F_{o}$ & 51 & 1.2 & 102 & 0.34 & 153 & 0.38 & & & & \\
\hline & \multirow{8}{*}{ 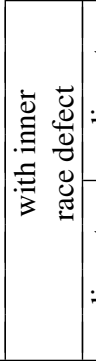 } & \multirow{4}{*}{ 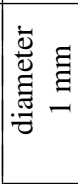 } & $F_{s}$ & 20.75 & 1.05 & 41.75 & 0.1 & 62 & 0.24 & & & & \\
\hline & & & $F_{o}$ & 54.5 & 0.68 & & & & & & & & \\
\hline & & & $F_{I}$ & 89 & 1.7 & & & & & 69 & 0.73 & 109.25 & 0.88 \\
\hline & & & $F T F$ & 7.5 & 0.1 & & & & & 12.75 & 0.2 & 27.5 & 0.09 \\
\hline & & \multirow{4}{*}{ 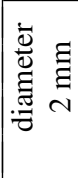 } & $F_{s}$ & 20.5 & 1.38 & 41.5 & 0.13 & 61.25 & 0.37 & & & & \\
\hline & & & $F_{o}$ & 54 & 0.78 & & & & & & & & \\
\hline & & & $F_{I}$ & 88.75 & 1.7 & & & & & 68.5 & 0.75 & 109.25 & 0.9 \\
\hline & & & $F T F$ & 7.75 & 0.12 & & & & & 13 & 0.2 & 27.75 & 0.1 \\
\hline \multirow{17}{*}{ 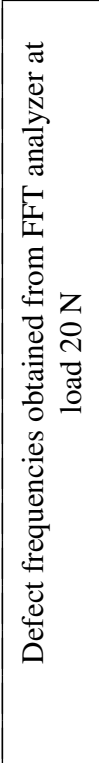 } & \multirow{3}{*}{\multicolumn{2}{|c|}{ Healthy }} & $F_{s}$ & 20.5 & 0.56 & 41.25 & 0.33 & 62.25 & 0.05 & & & & \\
\hline & & & $F_{o}$ & & & & & & & & & & \\
\hline & & & $F_{I}$ & & & & & & & & & & \\
\hline & \multirow{6}{*}{ 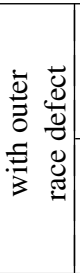 } & \multirow{3}{*}{ 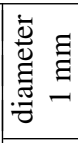 } & $F_{s}$ & 20.25 & 1.4 & 40.5 & 0.9 & 61.75 & 0.28 & & & & \\
\hline & & & $F_{o}$ & 51.25 & 1.9 & 102.5 & 0.58 & 153.75 & 0.25 & & & & \\
\hline & & & $F_{I}$ & & & & & & & & & & \\
\hline & & \multirow{3}{*}{ 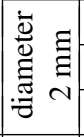 } & $F_{s}$ & 20.5 & 1.5 & 41 & 0.85 & 61 & 0.58 & & & & \\
\hline & & & $F_{o}$ & 51 & 1.73 & 102 & 0.8 & 153.25 & 0.78 & & & & \\
\hline & & & $F_{I}$ & & & & & & & & & & \\
\hline & & & $F_{s}$ & 20.25 & 1.98 & 40.5 & 0.17 & 60.7 & 0.4 & & & & \\
\hline & & $\begin{array}{ll}\bar{\Xi} & \Xi \\
\Xi & \Xi\end{array}$ & $F_{o}$ & 53.5 & 0.8 & & & & & & & & \\
\hline & \begin{tabular}{|cc}
$\overline{0}$ & $\overline{0}$ \\
$\Xi$ & 0 \\
0
\end{tabular} & : & $F_{I}$ & 88.75 & 1.72 & & & & & 68.75 & 0.76 & 108.5 & 0.91 \\
\hline & $\mid \begin{array}{ll}. \Xi & 8 \\
\Xi & 0 \\
= & 0\end{array}$ & & $F T F$ & 8 & 0.12 & & & & & 12.25 & 0.29 & 27.5 & 0.11 \\
\hline & 度惫 & & $F_{s}$ & 20.25 & 2.12 & 40.5 & 0.2 & 60.75 & 0.58 & & & & \\
\hline & & $\begin{array}{ll}\bar{\Xi} & \Xi \\
\Xi & \Xi\end{array}$ & $F_{o}$ & 53.75 & 0.89 & & & & & & & & \\
\hline & &.$\underset{\Xi}{\partial} \mathrm{N}$ & $F_{I}$ & 89 & 1.78 & & & & & 69.25 & 0.8 & 109 & 0.96 \\
\hline & & & $F T F$ & 7.75 & 0.16 & & & & & 12.5 & 0.32 & 28 & 0.14 \\
\hline
\end{tabular}




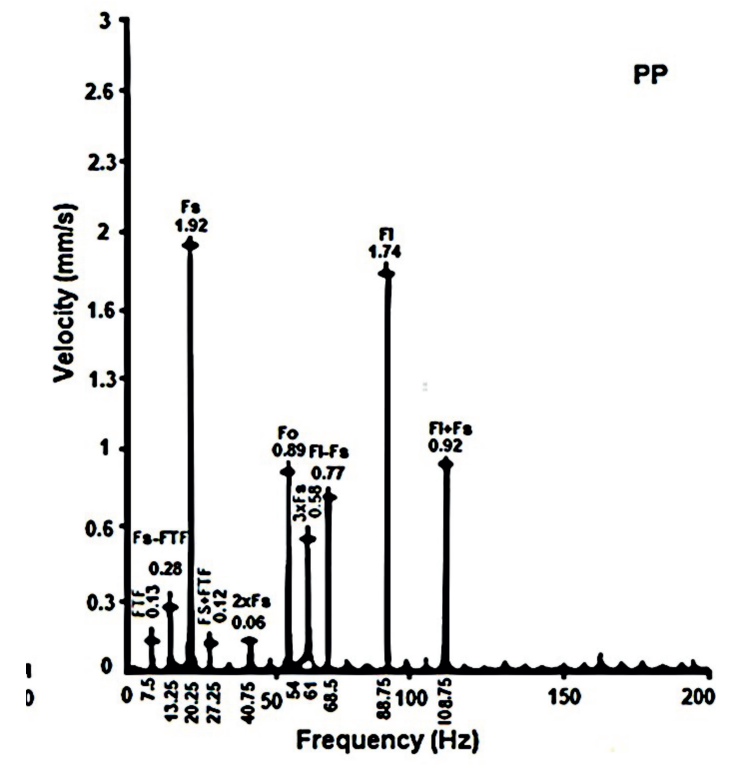

Fig. 8. Velocity Spectrum of $2 \mathrm{~mm}$ inner race defect for frequency $20 \mathrm{~Hz}$ at $15 \mathrm{~N}$.

as the applied load increases from $5 \mathrm{~N}$ to $20 \mathrm{~N}$. The peak amplitudes at sideband frequencies $\left(F_{I}-F_{s}\right.$ and $\left.F_{I}+F_{s}\right)$ increase with respect to the applied load. Test results reveal that higher radial loads produce higher acceleration levels. Therefore, a bearing with high load level can increase its wear rate [26]. Outer race frequency peak amplitude was observed with the introduction of an inner race defect. When the defect is on the outer race, the obtained results for the characteristic defect frequencies are below the calculated ones. However, when the defect is on the inner race, the experimental defect frequencies are above the values obtained by the analytical model cited in Section 2 [25]. FTF and its sidebands also observed during the testing of bearing with inner race defect for the high frequency of $20 \mathrm{~Hz}$ at all the radial loads. Peak amplitudes of FTF increase with respect to increase in load levels. A similar observation was visualized by Roque in [25].

\section{CONCLUSION}

Radial Polypropylene bearings were manufactured by machining and the dynamic performance was investigated by in-house developed test rig under dry condition. Experimental investigations were carried out to study the dynamic characteristics with respect to the defect size, operating frequency and load. Experimental results were compared to the White and Harris analytical model $[15,16]$. The obtained 
results using vibration monitoring test have shown that the analytical model of the fundamental defect frequencies closely matches with the test results of thermoplastic bearings.

The experimental investigations show that the overall vibration levels increase with respect to the increase of the size of the outer race defect. It has been, clearly, observed that the introduction of a defect in the inner-race produces a looseness of the cage and, hence results in modulation of fundamental train frequency.

Outer race frequency peak amplitude was observed with the introduction of inner race defect and its harmonics were not visualized. It has been observed, also, that the defective-inner-rice vibration peak amplitude frequency increases when the rotational frequency increases. The peak amplitudes at sideband frequency also enhance with respect to the increase of the operating frequency confirming the severity of defect at high speeds. When, the radial load increases, the amplitude of harmonics of the shaft rotational frequency increases. Peak amplitudes of Fundamental Train Frequency enhance with respect to the increase of the load levels.

In this work, it has been observed, that the Fast Fourier Transform frequency spectrums for new and defective polypropylene bearings lead to determine the location of the defect and its severity. Based on the obtained frequency spectrums, it is evident that each defect type has specific frequency plots, which can support to make an efficient diagnostic decision. Thereafter, developing a simulation model to investigate the dynamic behavior of thermoplastic bearings can extend this study.

\section{REFERENCES}

[1] W.A. Glaeser (1992) Polymeric Materials. In: Materials For Tribology. Tribology Series 20 177-210.

[2] J. Mcguinn (2011) Non-Metallic Bearings: An Alternative Worth Considering. Power transmission engineering 14-17.

[3] M.A. Abu-Zeida, S.M. Abdel-Rahmanb (2013) Bearing problems' effects on the dynamic performance of pumping stations. Alexandria 52(3) 241-248.

[4] Ch. Lalanne (2014) Mechanical Vibration and Shock Analysis. Fatigue Damage 4(3) $1-146$.

[5] R. Das, R. Kumar, P.P. Kundu (2014) Damping Evaluation of Linseed Oil-Based Engineering Elastomers by Vibration Response Method. ISRN Polymer Science 1-14.

[6] P.K. Prashant, V.K. Sharad (2014) Review of Fault Detection in Rolling Element Bearing. Journal of IJIRAE 1(5) 169-174.

[7] N. TANDON, B.C. NAKRA (1992) Vibration and acoustic monitoring techniques for the detection of defects in rolling element bearings - a review. Shock Vibr Digest 24 (3) 3-11.

[8] P.Y. KIM, I.R.G. LOWE (1983) A review of rolling element bearing health monitoring. 
In: Proceedings of Machinery Vibration Monitoring and Analysis Meeting, Vibration Institute, Houston, TX, 145-154.

[9] J. Mathew, R.J. Alfredson (1984) The condition monitoring of rolling element bearings using vibration analysis. Journal of Vibration, Acoustics Stress and Reliability in Design 106 447-53.

[10] P.D. McFadden, J.D. SMith (1984) Vibration monitoring of rolling element bearings by the high frequency resonance technique - a review. Tribology International 17(1) 3 10.

[11] P.Y. KIM (1984) A review of rolling element bearing health monitoring (II): preliminary test results on current technologies. In: Proceedings of Machinery Vibration Monitoring and Analysis Meeting, Vibration Institute, New Orleans, LA, 127-37.

[12] P.Y. KIM (1984) A review of rolling element bearing health monitoring (III): preliminary test results on eddy current proximity transducer technique. In: Proceedings of $3 \mathrm{rd}$ International Conference on Vibration in Rotating Machinery, York, UK, 119-25.

[13] A. MaAmar, B.C. Bouzgarrou, V. Gagnol, R. Fathallah (2017) Time Domain Stability Analysis for Machining Processes. In: Fakhfakh T., F. Chaari, L. Walha, M. Abdennadher, M. Abbes, M. Haddar (Eds) Advances in Acoustics and Vibration. Applied Condition Monitoring 5, Springer, Cham.

[14] M. Amarnath, R. Shrinidhi, A. Ramachnadra, S.B. Kandagal (2004) Prediction of defects in antifriction bearings using vibration signal analysis. Journal of IEI 85 88-92.

[15] J.P. Gerval, G. Morel, C. Querre (1994) Behaviour modelling and vibration analysis applied to predictive maintenance: different approaches leading to the same conclusion. In: OCEANS, 94. 'Oceans engineering for today's technology and tomorrow's preservation' Proceedings, 1, Fransa. I/544-I/546.

[16] G. White (1997) “Introduction to Machine Vibration”. DLI Engineering Corp.

[17] T.A. HARRIS (1991) "Rolling Bearing Analysis", 3-d Edition, John Wiley \& Sons, 672.

[18] N. Tandon, A. Choudhury (1997) An analytical model for the prediction of the vibration response of rolling element bearings due to a localized defect. Journal of Sound and Vibration 205(3) 275-92

[19] N. TANDOn, A. Choudhury (1998) A theoretical model to predict vibration response of rolling bearings to distributed defects under radial load. Journal of Vibrations and Acoustics 120 214-220.

[20] R.K.S. Raveendran, M.H. Azarian, C. Morillo, M.G. Pecht, K. Kida, E.C. SANTOS, T. HONDA, H. KoIKE (2013) Comparative evaluation of metal and polymer ball bearings. Wear 302 1499-1505.

[21] http://hbot3d.com/wp-content/uploads/2018/10/HBOT3D-Material-Catalogue-EN.pdf.

[22] P.D. MCFAdDEn, J.D. SMith (1984) Model for the vibration produced by a single point defect in a rolling element bearing. Journal of Sound and Vibration 96(1) 69-82.

[23] T.R. Kurfess, S. Billington, S.Y. Liang (2006) Advanced Diagnostic and Prognostic Techniques for Rolling Element Bearings. In: Wang L., Gao R.X. (eds) Condition 
Monitoring and Control for Intelligent Manufacturing. Springer Series in Advanced Manufacturing. Springer, London.

[24] H. Saruhan, S. SARdemir, A. IEK, I .Uygur (2014) Vibration Analysis of Rolling Element Bearings Defects. Journal of Applied Research and Technology 12 384-395.

[25] A.A. Roque, T.A.N. Silva, J.M.F. Calado, J.C.Q. Dias (2009) An Approach to Fault Diagnosis of Rolling Bearings. WSEAS transactions on systems and control 4(4) 188-197.

[26] D.H. Pandya, S.H. Upadhyay, S.P. Harsha (2014) Nonlinear dynamic analysis of high-speed bearings due to combined localized defects. Journal of Vibration and Control 20(15) 2300-2313. 